\title{
铬催化硝基化合物的脱氧硼氢化
}

\author{
张艳东朱守非* \\ (南开大学化学学院 元素有机化学国家重点实验室 天津 300071)
}

\section{Chromium-Catalyzed Deoxygenative Hydroboration of Nitro Compounds}

\author{
Zhang, Yandong Zhu, Shoufei* \\ (State Key Laboratory and Institute of Elemento-Organic Chemistry, College of Chemistry, Nankai University, Tianjin 300071)
}

伯胺类化合物是一类重要的功能分子, 在医药、农 药、材料、染料等领域广泛应用 ${ }^{[1]}$. 硝基化合物的还原 是制备伯胺直接有效的方法 ${ }^{[2]}$, 然而该类反应目前常用 的基于镍、钯、铂的异相催化氢化体系对于卤素、烯基、 炔基等官能团的兼容性差 ${ }^{[3]}$. 发展高效、官能团耐受性 好的硝基还原催化剂是充满挑战的重要研究方向.

由于 $3 \mathrm{~d}$ 金属(即第一过渡系金属)储量丰富、廉价易 得、生物兼容性好, 近年来基于 $3 \mathrm{~d}$ 金属催化剂的研究受 到广泛关注 ${ }^{[4]}$. 不少 $3 \mathrm{~d}$ 金属具有独特的开壳层结构和多 变的自旋态，通常表现出不同于其他过渡金属的独特的 催化性能 ${ }^{[5]}$. 虽然基于铁、钴、镍、铜等 $3 \mathrm{~d}$ 金属络合物 的均相催化剂在硝基还原中已有零星报道 ${ }^{[6]}$, 但是这些 催化剂普遍存在效率不高, 官能团耐受性不佳等问题. 四川大学化学学院曾小明课题组近年来致力于铬催化 反应研究 ${ }^{[7]}$, 发现铬催化剂在 $\mathrm{C}-\mathrm{H}$ 键官能团化、 $\mathrm{C}-\mathrm{C}$ 键偶联等反应中表现出独特的反应性, 最近该课题组又 发展了环状单胺基卡宾一亚胺双齿配体铬络合物催化剂 (CAAC-Cr), 实现了硝基化合物的脱氧嗍氢化还原为伯 胺的反应, 表现出优异的活性和化学选择性: 转化数 (产物与催化剂的物质的量之比)最高可达 180 万, 能够 耐受卤素、烯、炔、羧酸、酰胺等易于还原的官能团 (Scheme 1) ${ }^{[8]}$.

研究者根据以往的经验, 认为富电子的环状单胺基 卡宾(CAAC)配体可以增强金属中心铬的电子云密度, 对活化 HBpin 有利, 侧链的亚胺可以提供额外的配位 点, 使得配体与铬螯合配位, 有利于稳定活性催化物种. 据此, 研究人员制备了环状单胺基卡宾-亚胺配体和铬 的络合物(CAAC-Cr), 通过单晶表征了其结构, 通过磁
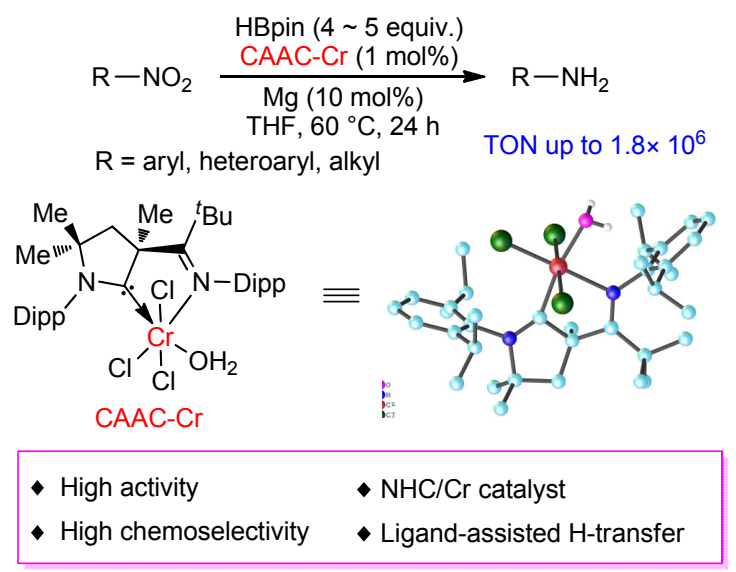

图式 1 环状单胺基卡宾的铬络合物催化硝基化合物的还原 反应

Scheme 1 CAAC-Cr-catalyzed reduction of nitro compounds 矩表征确定该三价铬络合物在基态时处于高自旋的四 线态. 进一步的研究表明, 上述铬络合物在 $\mathrm{Mg}$ 作为活 化试剂、HBpin 作为还原剂的条件下, 可以高效地将硝 基化合物还原为伯胺, 配体加速效应明显. CAAC-Cr 催 化硝基化合物的还原具有优异的化学选择性, 可以兼容 卤素、羟基、胺基、烯基、炔基、羧基、酰胺等一系列 活性基团, 还适用于多种杂芳环, 包括吡啶、喹啉、苯 并吡嗪等(Scheme 2). 除了硝基芳烃，该催化体系还可 以应用于硝基烷烃的还原制备脂肪伯胺. 研究者还成功 将该反应用于多种生物活性分子的简洁合成.

研究人员还对机理进行了初步研究. 他们通过 X射 线光电子能谱对催化剂进行分析, 推测反应可能由零价 铬物种启动; 通过动力学实验获得了各反应组分的动力

* Corresponding author. E-mail: sfzhu@nankai.edu.cn. Published online February 18, 2021. 


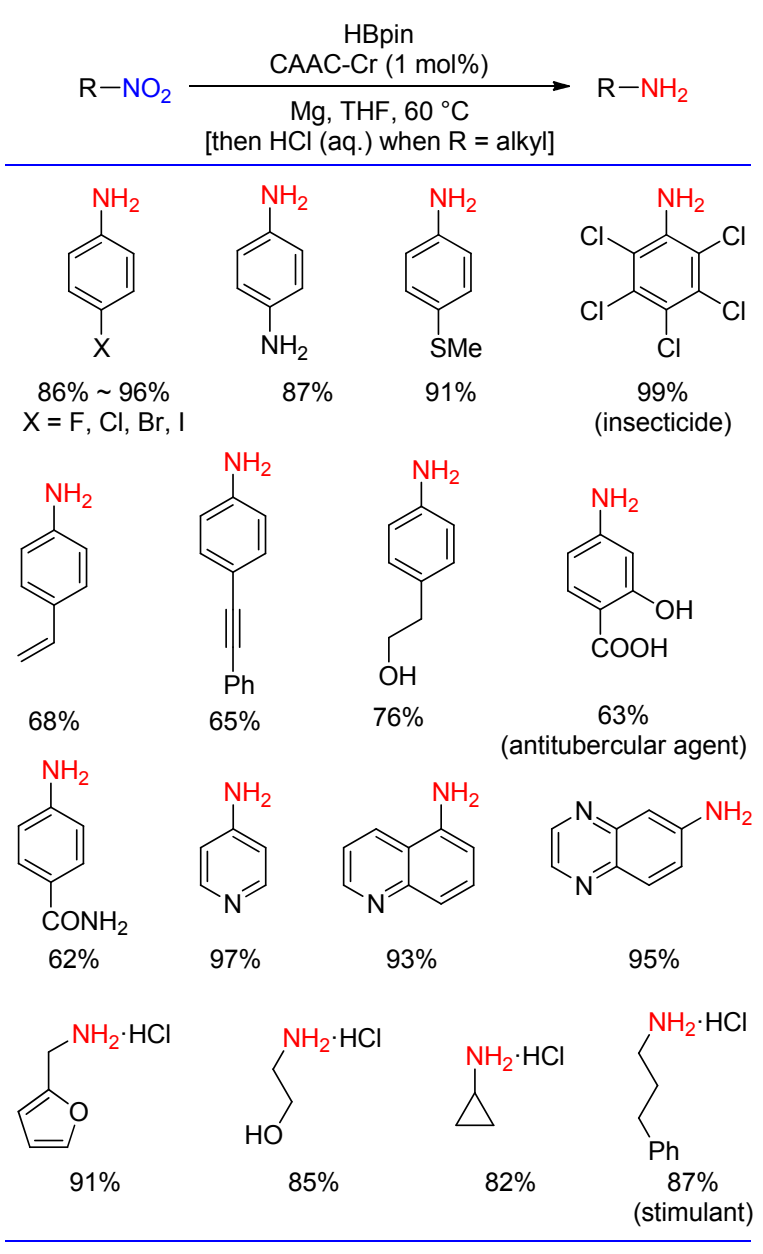

图式 2 CAAC-Cr 催化硝基还原产物举例

Scheme 2 Representative examples of CAAC-Cr-catalyzed reduction of nitro compounds

学级数, 发现缺电子的硝基苯具有较快的反应速率; 通 过 Eyring 方程解得反应的吉布斯自由能变约为 122.5 $\mathrm{kJ} \cdot \mathrm{mol}^{-1}$. 此外, 他们还通过密度泛函理论(DFT)计算研 究了反应历程 (Scheme 3), 认为反应从零价铬启动, 催 化循环主要包括两个连续的硼氢化脱氧及氮化铬还原 历程, 其中包含了新颖的卡宾配体 CAAC 辅助的氢转 移, 反应的决速步计算活化能与实验值基本相符. 轨道 分析发现, 铬原子未成对的 $\mathrm{d}$ 电子高度极化进入卡宾碳 空的 $\mathrm{p}$ 轨道, 暗示了这类卡宾具有部分自由基的特征, 这有可能促进了氢转移.

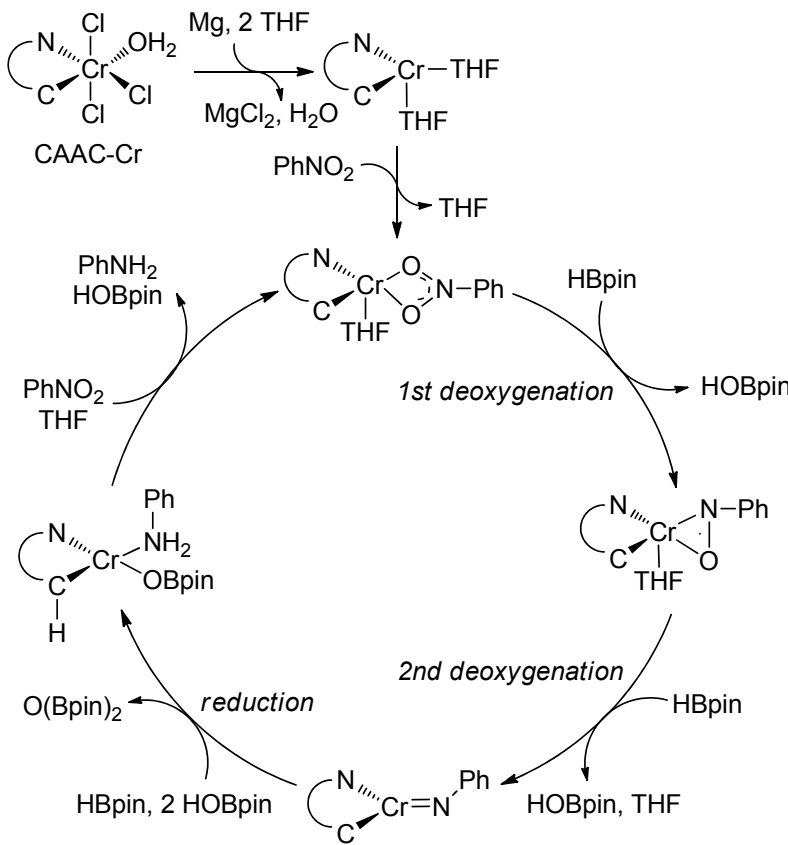

图式 3 建议机理

Scheme 3 Proposed mechanism

总之，曾小明课题组发展了环状单胺基卡宾一亚胺 配体铬络合物催化的硝基化合物还原为伯胺的反应. 该 催化体系表现出优异活性和官能团耐受性，为伯胺的合 成提供了新的有效途径. 机理研究进一步深化了对铭催 化反应规律的认识. 揭示活性铬催化剂结构, 阐明铬催 化剂高活性和高选择性的化学基础，使用更为经济和绿 色的还原剂(如 $\mathrm{H}_{2}$ ) 将是该反应未来研究的重点.

\section{References}

[1] Ley, C. Ullmann's Encyclopedia of Industrial Chemistry, Verlag Chemie, Weinheim, Germany, 2012, Vol. A2, pp. 647 718.

[2] Orlandi, M.; Brenna, D.; Harms, R.; Jost, S.; Benaglia, M. Org. Process Res. Dev. 2018, 22, 430.

[3] Goksu, H.; Sert, H.; Kilbas, B.; Sen, F. Curr. Org. Chem. 2017, 21, 794.

[4] Chirik, P.; Morris, R. Acc. Chem. Res. 2015, 48, 2495.

[5] Chirik, P. J. Angew. Chem., Int. Ed. 2017, 56, 5170

[6] Formenti, D.; Ferretti, F.; Scharnagl, F. K.; Beller, M. Chem. Rev. 2019, 119, 2611.

[7] Zeng, X. Synlett 2020, 31, 205

[8] Zhao, L.; Hu, C.; Cong, X.; Deng, G.; Liu, L. L.; Luo, M.; Zeng, X. J. Am. Chem. Soc. 2021, 143, 1618 